\title{
Development of the Z-score for the measurement of myocardial thickness by means of two-dimensional echocardiography in normal fetuses.
}

\author{
Luciane Rocha $^{1}$, Paulo Zielinsky ${ }^{2}$, Luiz Henrique Nicoloso ${ }^{2}$, and Edward Araujo Júnior ${ }^{3}$ \\ ${ }^{1}$ Federal University of Amazonas \\ ${ }^{2}$ Affiliation not available \\ ${ }^{3}$ Federal University of São Paulo (UNIFESP)
}

July 7,2020

\begin{abstract}
In the current literature, we observed a tendency to describe normal values of echocardiographic measurements by means of the Z-score. In fetal cardiology, these Z-score equations are still being established. Measurement of myocardial thickness is an important assessment especially in fetuses of diabetic pregnant women because of the risk of developing myocardial hypertrophy secondary to elevated maternal blood glucose levels. To determine the percentiles and to develop the Z-score equations of right and left ventricular lateral wall and interventricular septum measurements using two-dimensional echocardiography in normal fetuses between 24 and 34 weeks of gestation. This is a prospective cross-sectional study that was performed in single fetuses with normal heart and in non-diabetic pregnant women. Measurements of the lateral wall of the right and left ventricles and the interventricular septum were made. 873 pregnant women were included. We determined the percentiles of the measurements for each gestational age. The Z-score equation was developed for each of the measurements: right ventricular lateral wall measurement $[\mathrm{RVLW}=\mathrm{x}-(-1+0.109 * \mathrm{GI}) / 0.4]$, left ventricle lateral wall measurement $[\mathrm{LVLW}=\mathrm{x}-(-1.366+0.12 *$ GI) / 0.43] and the interventricular septum in the four-chamber plane [IVS4ch $=(\mathrm{x}-(-1,113+0.107 * \mathrm{IG}) / 0.4]$ and the interventricular septum in the left ventricular outflow tract plane [IVSLVOT $=(\mathrm{x}-(-0.581+0.084 * \mathrm{GI}) / 0.35]$. The present study allowed to demonstrate the percentiles and the Z-score equations for each of the measures studied.
\end{abstract}

\section{Hosted file}

article_USG.docx available at https://authorea.com/users/339553/articles/465725-developmentof-the-z-score-for-the-measurement-of-myocardial-thickness-by-means-of-two-dimensionalechocardiography-in-normal-fetuses

\section{Hosted file}

Tables_USG.docx available at https://authorea.com/users/339553/articles/465725-developmentof-the-z-score-for-the-measurement-of-myocardial-thickness-by-means-of-two-dimensionalechocardiography-in-normal-fetuses

\section{Hosted file}

Figures_USG.docx available at https://authorea.com/users/339553/articles/465725-developmentof-the-z-score-for-the-measurement-of-myocardial-thickness-by-means-of-two-dimensionalechocardiography-in-normal-fetuses 